\title{
Penerapan Teknik Art Therapy untuk Mengurangi Kecemasan Sosial terhadap Korban Cyberbullying
}

\author{
Yona Mita Soma ${ }^{1^{*}}$, Yeni Karneli ${ }^{2}$ \\ Universitas Negeri Padang ${ }^{12}$ \\ *) Correspondence Author, e-mail: yonamitasoma@gmail.com
}

\begin{abstract}
Abstrak: Tulisan ini bertujuan untuk mengetahui penerapan teknik art therapy untuk mengurangi kecemasan sosial terhadap korban cyberbullying. Teknik art therapy adalah sebuah teknik terapi dengan menggunakan media seni, proses kreatif, dan hasil dari seni untuk mengeksplorasi perasaan, konflik emosi, meningkatkan kesadaran diri, mengontrol perilaku, mengembangkan kemampuan sosial, meningkatkan orientasi realitas, mengurangi kecemasan dan meningkatkan penghargaan diri. Art therapy adalah sebuah proses penyembuhan yang dilakukan dengan membuat sebuah karya seni yang kreatif. Proses penyembuhan ini berguna dalam meningkatkan kualitas kehidupan. Art therapy sangat membantu dalam mengatasi gangguan emosi, menyelesaikan konflik, menambah wawasan, mengurangi perilaku bermasalah, serta meningkatkan kebahagiaan hidup
\end{abstract}

Kata kunci: Teknik art therapy, kecemasan sosial, korban cyberbullying

Article History: Received on 05/03/2020; Revised on 02/06/2020; Accepted on 12/06/2020; Published Online: 11/7/2020.

(a) This is an open access article distributed under the Creative Commons Attribution License, which permits unrestricted use,
distribution, and reproduction in any medium, provided the original work is properly cited. (C2020 by author.

Tidak dapat dipungkiri bahwa seiring dengan berkembangnya zaman, teknologi semakin canggih. Perkembangan teknologi memberikan kemudahan bagi masyarakat untuk saling berkomunikasi dan menyebarkan informasi. Namun perkembangan teknologi selalu memiliki dampak positif dan negatif. Jika dampak positifnya adalah memberikan kemudahan untuk saling berkomunikasi, sedangkan salah satu dampak negatifnya yaitu adanya cyberbullying. Hampir semua masyarakat terhubung dengan yang namanya internet dan media sosial. Internet, ponsel, dan teknologi komunikasi lain berpotensi menimbulkan interaksi berbahaya yang beresiko pada keselamatan dan kesejahteraan emosional (Li, Cross \& Smith, 2012).

Selain itu media sosial sebagai media untuk berkomunikasi jarak jauh, hanya dengan menggunakan smarphone dan koneksi internet, orang- orang dapat berkomunikasi dengan mudah melalui akun media sosial seperti blackberry massenger, facebook, twitter, path, instagram, line, skype, dan lain sebagainya (Arista, 2015). Efek negatif dalam bermain media sosial adalah adanya perilaku kekerasan, namun bukan kekerasan fisik, melainkan disebut dengan cyberbullying. Cyberbullying adalah kejahatan yang dilakukan dengan cara mempermalukan, mengancam, menghina, menakut- nakuti, atau bahkan menyebabkan kerugian bagi seseorang sehingga orang tersebut berada 
dalam masalah. Hal ini termasuk mengirimkan pesan berupa konten yang menyakitkan dan merendahkan (Hinduja \& Patchin, 2010). Tentunya tindakan cyberbullying ini menimbulkan dampak bagi korbannya. Dampak yang mungkin tejadi bisa beraneka ragam seperti, menurunnya rasa percaya diri, merusak emosi dan psikologis, kesedihan mendalam, frustasi, kecemasan, dan lain sebagainya.

Berdasarkan penelitian yang telah dilakukan oleh Gopalakrishnan \& Sundram (2014) menyebutkan bahwa ada hubungannya antara cyberbullying dan kecemasan dengan hasil yang diperoleh yaitu, laki- laki menunjukkan kecemasan lebih tinggi 44, 89\% daripada perempuan 40,82\%. Kemudian penelitian yang dilakukan oleh Hinduja \& Patchin (2010) dengan hasil 20\% korban cyberbullying pernah berpikir ingin mencoba bunuh diri dan 19\% melaporkan untuk mencoba bunuh diri. Hal ini disebabkan jika kecemasan yang diakibatkan cyberbullying tidak ditangani serta diatasi dengan baik, maka kecemasan tersebut akan meningkat dan mengakibatkan korban menjadi depresi bahkan bisa melakukan tindakan bunuh diri.

Selanjutnya penelitian yang dilakukan oleh Jernaro et al., (Gerald, K, 2008) menyatakan bahwa yang menjadi korban cyberbullying menunjukkan gangguan gejala klinis seperti 9,8\% mengalami depresi, 17, 5\% memiliki skor tinggi dalam status kecemasan sosial dan 20,5\% menunjukkan ciri- ciri kecemasan, sehingga dapat disimpulkan bahwa sebagian besar korban cyberbullying mengalami kecemasan. Salah satu dampak yang timbul pada korban cyberbullying yaitu kecemasan sosial. Kecemasan sosial menurut konsep Communication Aprrehension (CA)didefenisikan sebagai tekanan psikologis yang dialami seseorang sebagai reaksi terhadap kehadiran orang lain. Ini juga berkaitan dengan kecemasan komunikatif yaknik digambarkan sebagai rasa takut yang berkaitan dengan berkomunikasi dengan orang lain. Apabila digambarkan, orang- orang yang mengalaminya cenderung akan menghindari interaksi sosial bila memungkinkan, berbicara lebih sedikit jika dibutuhkan, untuk terlibat dalam percakapan kurang lancar, dan pengalaman tekanan psikologis yang berat (Littlejohn, 2009).

Pada implementasinya, kecemasan sosial digambarkan dalam penelitian sebagai bentuk perasaan serta perilaku seseorang berharap atau berusaha agar tidak bertemu dengan orang lain karena mereka memiliki perasaan takut atau khawatir jika berada pada situasi sosial apapun. Kemudian menurut Triantoro \& Astrid (2014) mengatakan bahwa melalui art therapy mampu menurunkan tingkat kecemasan korban bullying dalam kelompok eksperimen.

\section{METODE}

Penelitian ini menggunakan jenis atau pendekatan studi kepustakaan (Library Research). Studi kepustakaan merupakan suatu studi yang digunakan dalam mengumpulkan informasi dan data dengan bantuan berbagai macam material yang ada di perpustakaan seperti dokumen, buku, majalah, kisah- kisah sejarah, dan sebagainya. Menurut (Syaodih, 2009) jenis penelitian ini adalah penelitian kepustakaan, yaitu serangkain penelitian yang berkaian dengan metode pengumpulan data perpustakaan, atau penelitian yang objek penelitiannya dieksplorasi melalui berbagai informasi perpustakaan (buku atau jurnal ilmiah). Penelitian perpustakaan atau tinjauan pustaka 
adalah studi yang secara kritis memeriksa pengetahuan, ide atau temuan yang terkandung dalam tubuh literatur berorientasi akademik.

\section{Pembahasan}

\section{Kecemasan Sosial Korban Cyberbullying}

Kecemasan sosial adalah kondisi dimana individu menghindari hubungan sosial dan mengalami perasaan stres yang bisa membawa hubungan buruk dalam interaksinya dengan teman sebaya. Kecemasan sosial bisa merusak hubungan dengan orang- orang yang seharusnya dekat dan memiliki kontribusi untuk mendukung individu (Grace \& Lopez, 1998). Terdapat beberapa aspek kecemasan sosial menurut Grace \& Lopez (1998), yaitu:1) Ketakutan akan evaluasi negatif. Kondisi dimana individu mengalami ketakutan, kekhawatiran, kecemasan mengenai evaluasi negatif dari teman sebaya. 2) Penghindaran sosial dan kesulitan baru.3) Rasa gugup dan menghindar terhadap orang atau situasi yang baru. 4) Penghindaran sosial dan kesulitan umum. 5) Rasa tidak percaya diri dan tidak nyaman dengan orang yang dikenal atau situasi umum.

Willard menjelaskan bahwa cyberbullying yaitu berbicara memfitnah, termasuk bullying, pelecahan atau diskriminasi, dan mengungkapkan informasi pribadi yang berisi komentar yang menyinggung, vulgar, dan menghina (Sharrif, 2008). Menurut Willard, terdapat beberapa bentuk cyberbullying (Kowalski, Limber \& Agaston, 2008), yaitu sebagai berikut:(1)Flaming. Flaming mengacu pada kebencian antara dua atau lebih individu melalui teknologi komunikasi. Flaming dapat terjadi di chat room atau di grup diskusi. Flaming ini berupa mengirimkan pesan yang menghina, menggunakan bahasa yang kasar, dan perdebatan tanpa dasar yang kuat. (2)Harrasment (pelecahan). Bentuk harrasment berupa posting berulang kali di suatu forum atau mengirimkan pesan yang tidak pantas melalui media sosial. (3)Denigration (pencemaran nama baik). Denigration adalah menyampaikan informasi yang tidak benar mengenai individu yang bertujuan merusak reputasi atau nama baik. (4)Impersonation (peniruan). Impersonation yaitu menggunakan akses akun orang lain tanpa meminta izin. Mengubah privasi akun orang lain juga termasuk dalam impersonation. Kemudian, pelaku cyberbullying menyebarkan informasi tidak sesuai kepada orang lain. Contoh impersonation adalah menggunakan password korban untuk mengakses akunnya. (5)Outing and Trickery (menyebarkan rahasia pribadi dan penipuan). Outing and Trickery mengacu pada membagi informasi pribadi yang memalukan kepada orang lain. (6)Exclusion/ Ostracism (pengeluaran). Exclusion/ Ostracism merupakan pengucilan secara online yang terjadi dalam lingkungan yang dilindungi oleh kode sandi. (7)Cyberstalking. Cyberstalking mengacu pada penggunaan komunikasi elektronik untuk menguntit, melecehkan, dan mengancam yang dilakukan secara berulang kali. (8)Happy Slaping. Remaja biasanya melakukan intimidasi terhadap remaja lain dengan menggunakan kamera handphone (ponsel). Intimidasi yang dilakukan pelaku cyberbullying berupa ancaman dan menyebarluaskan foto atau video yang tidak baik.

Dampak yang dirasakan korban setelah menerima perilaku cyberbullying antara lain merasa tidak tenang, merasa takut apabila diganggu lagi, merasa tidak aman ketika menghadapi situasi yang sama, memilih menyendiri, lebih berhati- hati dalam bertindak agar tidak dinilai salah, menutup diri dari lingkungan, merasa malu, merasa tidak 
percaya diri. Menurut Olweus (Faryadi, 2011) menyatakan bahwa korban cyberbullying memiliki beberapa karakteristik diantaranya merasa gelisah, merasa tidak aman, tidak bahagia dan memiliki harga diri yang rendah, berhati- hati, peka, pendiam, menarik diri dari lingkungan dan pemalu, merasa tertekan dan terlibat dalam pikirannya untuk bunuh diri, serta tidak memiliki teman baik untuk membahas suatu masalah.

\section{Teknik Art Therapy}

Art therapy dapat dinilai sebagai suatu bentuk bahasa visual individu untuk mengekspresikan pikiran dan perasaan yang tidak bisa mereka ungkapkan. Selain itu art therapy dapat menjadi cara dalam mengkomunikasikan pengalaman yang sulit untuk diverbalisasi, seperti kekerasan fisik atau seksual, trauma, kesedihan, kecemasan, serta pengalaman emosional yang komplek. Art therapy merupakan bentuk terapi yang melibatkan proses seni, seperti menggambar sebagai wujud simbolis dari hubungan terapeutik untuk membantu terapis memperoleh pemahaman diri maupun tekanan yang dialami oleh klien. Art therapy mulai banyak diaplikasikan pada masalah klien dengan gangguan psikologis, salah satunya yaitu penerapan art therapy pada gangguan kecemasan.

Art therapy adalah bentuk terapi yang dilakukan dengan menggunakan potensi manusia agar dapat menjadi lebih kreatif melalui proses menghasilkan suatu karya seni (Malchiodi, 2003). Menurut Malchiodi (2003) art therapy merupakan salah satu teknik yang digunakan dalam pengobatan, terutama dalam membantu konseli untuk dapat mengeksternalisasi pengalaman dan perasaannya melalui suatu bentuk karya visual. Kegiatan membuat suatu karya visual dapat dilakukan dengan menggambar, melukis, serta membuat patung. Penggunaan teknik menggambar dapat dijadikan sebagai salah satu alteratif intervesni untuk menangani korban cyberbullying yang mengalami kecemasan sosial. Kegiatan menggambar menyediakan ruang bagi korban untuk menceritakan pengalaman dan mengurangi reactivity (ingatan mengenai kecemasan) melalui visual reexposure (gambar yang mengembalikan situasi cemas) dalam media menggambar (Malchiodi, 2003).

Disisi lain seni dipercaya dapat memberikan citra diagnostik budaya dan individu, serta memberikan kesembuhan bagi kesehatan mental dan fisik. Studi menunjukkan bahwa upaya seni dapat mengurangi keluhan stres dan kesehatan, meningkatkan fungsi kekebalan tubuh, memberikan manfaat fisik dan psikologis, dan bahkan membantu orang- orang untuk hidup lebih lama. Seni juga menyediakan akses ke beberapa mode intelijen, komunikasi dan pemecahan masalah (Serlin, 2007). Menurut Gross \& Haynes (1998) terapi seni dapat digunakan untuk memanfaatkan respons relaksasi tubuh, misalnya dengan menggambar dhihipotesiskan untuk memfasilitasi laporan verbal secara emosional yang sarat dengan beberapa cara seperti pengurangan kecemasan, membantu merasa nyaman dengan terapis, meningkatkan pengambilan memori, mengatur narasi, dan mendorong untuk menceritakan lebih banyak detail daripada hanya dalam wawancara verbal Berdasarkan hasil data bahwa art therapy dapat membantu mengurangi kecemasan sosial korban cyberbullying. Karena korban dapat mengekspresikan perasaan dan emosinya terkait tindakan cyberbullying yang pernah dialaminya. 


\section{KESIMPULAN}

Kesimpulan yang dapat dipetik dari penelitian ini, yaitu dengan menggunakan teknik art therapy dapat mengurangi kecemasan sosial korban cyberbullying. Ada banyak jenis teknik art therapy, salah satunya yaitu menggambar. Maka melalui menggambar sebagai alternatif penanganan untuk korban cyberbullying yang mengalami kecemasan sosial mampu mengekspresikan perasaan terpendam korban mengenai kecemasan sosialnya, sehingga tingkat kecemasan tersebut dapat menurun. Karena korban cyberbullying yang mengalami kecemasan sosial perlu mendapatkan bantuan agar dirinya mampu mengatasi ketakutan, kekhawatiran, dan kecemasan yang dirasakan.

\section{REFERENSI}

Arista, N.M (2015). Studi Komparasi Perbandingan Dampak Media Sosial Terhadap Perilaku Bullying Remaja. Jurnal Kesejahteraan Keluarga Dan Pendidikan, 5(1), 26- 30. https://doi.org/https://doi.org/10.21009/JKKP.022.05

Faryadi, Q. (2011). Cyberbullying and Academic Performance. International Journal of Computational Engineering Research, 1 (1), 23-30. Retrieved from http://www.ijceronline.com

Gerald, K \& Gerald, D. (2008). Konseling Anak- Anak. Yogyakarta: Pustaka Belajar.

Gopalakrishnan C, \& Subramanian S. Antimicrobial activities of Garcinia mangostana. (2014). Planta Medica. 48(1): 59-60.

Grace, A.M.L., \& Lopez, N. (1998). Social Anxiety Among Adolescents: Linkages with Peer Relations and Friendships. Journal of Abnormal Child Psychology, 26(2), 83-94.

Gross, J., \& Haynes, H. (1998). Drawing Facilitates Children's verbal reports of emotional laden events. Journal of Experimental Psychology, 4, 163- 179.

Hinduja, S., \& Patchin, J. W. (2010). Cyberbullying: A review of the legal issues facing educators. Preventing School Failure, 55 (2), 1-8.

Kowalski, R.M., Limber, S.P., \& Agaston, P.W. (2008). Cyberbullying: Bullying in the digital age. New Jersey: Wiley- Blackwell.

Li, Q., Cross, D., \& Smith, P.K. (2012). Cyberbullying in the Global Playground: Research from International Perspektives. New Jersey: Blackwell Publishing.

Littlejohn, Stephen W., \& Karen A. Foss. (2009). Teori Komunikasi Theories of Human Communication edisi Sembilan. Jakarta: Salemba Humanika.

Malchiodi, C.A. (2003). Handbook of Art Therapy. New York: Guilford Press.

Serlin, I. A. (2007). Why is art important for psychology? The Arts Therapies: Whole Person Integrative Approaches To Healthcare. Theory and Practice of Art Therapist.

Sharrif, S. (2008). Cyber-bullying: issue and solutions for the school, the classroom and the home. New York: Taylor \& Francis.

Syaodih, N. (2009). Metode Penelitian Pendidikan. Bandung: Remaja Rosdakarya.

Triantoro, S., \& Astrid, Y. (2014). The efficacy of art therapy to reduce anxiety among bullying victims. International Journal of Research Studies in Psychology, 3(4), 77-88. 